\title{
Shape of Training: the right people with the right skills in the right place
}

\author{
R E Klaber, ${ }^{1}$ D E Lumsden, ${ }^{2}$ C Kingdon ${ }^{3}$
}

\section{INTRODUCTION}

A medical student entering medical school in 2014 will become a consultant sometime around 2027. The whole face of healthcare will have changed by then. The population is ageing, there are increasing numbers of people with multiple comorbidities and patients are increasingly demonstrating greater expectations of the quality of healthcare they receive. In addition, rapid technological and therapeutic advancement is counterbalanced by growing financial pressures. How we best adapt our workforce development and education strategies to be able to meet the future healthcare needs of the population is a huge challenge.

The training of doctors has received a lot of public and professional attention in the last decade with a series of in-depth reviews of various aspects of medical training both in the UK and internationally. ${ }^{1} 2$ A common thread in each of these has been to highlight the lack of flexibility in medical training and the slow response of the profession to change. Where change has been introduced, problems with consultation, implementation and other process issues ${ }^{34}$ have led to a sense of suspicion, if not outright resistance to change, among some medical professionals.

\section{KEY RECOMMENDATIONS OF THE SHAPE OF TRAINING REVIEW}

It is against this backdrop that the most recent review of medical training in the UK, the Shape of Training Review (SOT), chaired by Professor David Greenaway, was published in November 2013. The $^{5}$ key messages for postgraduate medical education from this review are the following:

- Patients' needs are changing and the medical workforce needs to change to meet that demand-more doctors are going to need to have a 'broad-based'

\footnotetext{
${ }^{1}$ Department of Paediatrics \& Child Health, Imperial College Healthcare NHS Trust, St Mary's Hospital, London, UK; ${ }^{2}$ Department of Paediatrics and Child Health, Evelina London Children's Hospital, London, UK; ${ }^{3}$ Department of Paediatrics \& Child Health, Evelina London Children's Hospital, London, UK

Correspondence to Dr Robert Edward Klaber, Department of Paediatrics \& Child Health, Imperial College Healthcare NHS Trust, St Mary's Hospital, London W2 1NY, UK; robert.klaber@imperial.nhs.uk
}

training that allows them to offer highquality general care in varied settings.

- Medical career pathways will need to be less rigid and allow doctors to change direction, acquire new skills and adapt over a working lifetime.

- Academic and subspecialty training must be preserved while at the same time specific training and workforce development priorities should be determined in line with local healthcare needs.

- Subspecialisation should take place once the formal 'general' specialty training process has been completed (ie, in the UK-Certificate of Specialty Training (CST)). While it has been widely perceived that the major driver for this has been the recognition of the need to reintroduce generalism to adult medicine, this is not specifically stated in the report that promotes the need for generalism in all specialties. The implication is that it is likely that this subspecialty training would need to be funded by the employer and accredited through a process called credentialing.

\section{INCREASING GENERALISM}

So, how does the SOT change anything for paediatrics and child health? All doctors training in paediatrics in the UK are currently expected to maintain general competencies, ultimately being awarded a Certificate of Completion of Training in General Paediatrics, with additional recognition of subspecialty training for those completing a recognised subspecialty training scheme (under the auspices of the National Training Number Grid Scheme). A parallel can be drawn between this additional recognition and the formalisation of additional credentialing suggested by SOT, though the two are not directly interchangeable. As of the 2011 Royal College of Paediatrics and Child Health (RCPCH) census, ${ }^{6}$ of the 4605 career grade paediatricians $(3418$ of whom where consultants, 1067 staff, associate specialist or specialty doctors) only 1400 $(\sim 30 \%)$ were working as subspecialists. This number had risen from 700 ( 19\%) in 2001, with an increase in total career grade paediatricians from 3621 during this same period. While specialists have increased as a proportion of the paediatric workforce in the UK in the last 1015 years, there has not been the exodus away from generalism seen in adult practice. Does SOT present a solution to a problem we do not currently face within paediatrics and child health?

\section{DEVELOPING A WORKFORCE FOR CHILD HEALTH}

While much of the discussion around SOT has focused on the emphasis on redressing the imbalance between specialist and generalist training, it is important not to lose sight of the body of recommendations as a whole. Central to the proposal is the grouping of training into patient care themes, one of these being child health. A move to a focus on exploring what sort of workforce is needed to provide high-quality child health, rather than solely on the training of paediatricians, is to be warmly welcomed. Paediatrician support of opportunities for general practitioners (GPs) and other clinicians working in primary care to build confidence and capability in paediatrics and child health is essential. Child health skills must also be bolstered across other specialties too, with significant numbers of children on a daily basis receiving care from anaesthetists, orthopaedic surgeons, plastic surgeons, and so on.

This fits in well with the plans of $\mathrm{RCPCH}(\mathrm{UK})$ to include a broader constituency than just paediatricians. Paediatricians are far from the only providers of child healthcare across the world, and indeed, the majority of child healthcare is delivered in the primary care setting and by parents and carers themselves.

Greater flexibility in training also benefits the development of a workforce for child health, with SOT proposing that doctors will be able to more easily transfer recognition of relevant competencies achieved from one stream of training to a new area of practice. This will hopefully encourage more trainees to feel able to transfer across training schemes without the need to 'reset the clock' on their training time. In addition, the notion of flexibility and life-long learning should encourage trainees, as well as trained doctors, to think about developing research and academic training opportunities throughout their careers. The current National Institute for Health Researchfunded academic clinical fellow/lecturer scheme that facilitates trainees moving between clinical and academic training will fit easily into the SOT approach to training and learning. 


\section{LEARNING ACROSS ORGANISATIONAL BOUNDARIES}

SOT also recognised the future shift of focus away from hospital-delivered care towards more services being delivered on a local and community basis. It acknowledged that modern training pathways remain largely segregated on the basis of historic boundaries between specialties, but in many ways the review is fairly unimaginative with suggestions as to how this might be done; "Doctors would benefit from training in themed areas relevant to patients rather than in specialties". ${ }^{5}$

With its strong general paediatrics base, paediatrics and child health has an outstanding opportunity to lead the way in developing integrated training programmes that will meet the child health needs of the future. There is increasing work within the UK looking at joint programmes of learning for GP trainees and paediatric trainees, ${ }^{7}$ and paediatric consultants and qualified GPs, ${ }^{8}$ based in primary care. These take the approach of training 'in and for' integrated models of care, and as their scope widens their impact on the future shape of training programmes will grow.

One welcome proposal from SOT, which in the short term may be an important stepping stone for trainees to explore new ways for working, is for an optional flexible year that could 'be spent working in a related speciality or undertaking leadership or management work'. This could be taken any time during broad-based training. Current arrangements to take up such training opportunities require formal application from a trainee for time 'out of programme', and depending on service pressures that can be difficult to approve. Explicitly including a year of flexible training within a training programme should help to ensure that the invaluable learning opportunity a year such as this affords is accessible to all, and not seen as a dispensable extra or as restricted to an exceptional few. This could be especially valuable in a 'run through' specialty like paediatrics, which can seem inflexible and too structured to some.

\section{LIFE-LONG LEARNING AND CREDENTIALING}

One of the more controversial recommendations from SOT is the shifting of subspecialty training to beyond the point of 'completion of training' (post the proposed CST in the UK). Leaving aside the crucial questions as to how this training would be funded and accessed, the introduction of programmes of 'credentialing' is an appealing way to freshen the often unimaginative point collecting approach that the profession has taken to continuing professional development. However, the potential exists for this to be seen as a devaluation of the role of the generalist. At present, training for general paediatrics in the UK is of equivalent length to training for the subspecialist. Most clinicians would consider general paediatrics to be a subspecialty in its own right, and some would argue that it can take longer to train a generalist compared with a specialist. The next few years therefore present an important opportunity for both general paediatricians and subspecialty paediatricians to re-examine their roles and to understand more accurately what the future service needs will be. This might offer an exciting opportunity to look at current training opportunities such as the SPIN (SPecial INterest) modules. One could envisage that both trainees and trained doctors will seek to use the framework of SPIN to develop their subspecialty skills. Thought should go into how this might be expanded and developed to allow quality improvement projects, research, and other learning and development opportunities to feed into SPIN. This would make it a useful mechanism not just for credentialing but also a chance to improve services and experiences for children and their families. In addition, working to increase connections across the primary-secondary care interface could well become a further area that doctors will seek to develop as their subspecialty 'credential'. Patient and parent input into this will be key, and early engagement with users is essential.

\section{CONCLUSIONS}

There is a risk that the SOT recommendations, as laudable as many of them are, will not gain enough traction within the health service to be implemented. The principles around flexibility within training, fresh approaches to life-long learning and taking new approaches to train in and for integrated care are very sound. The modern workforce that cares for children and young people needs to transcend traditional boundaries and has to start to challenge old assumptions about who delivers care and in which place. In order to equip our current and future trainees to meet these challenges, we need to start that process of change now. We all have a responsibility to ensure that these important education and training issues remain central to discussions about the future of the health service. Without such positive engagement, change is likely to happen to us as a workforce and not for us as advocates for child health.

Competing interests REK is the RCPCH Officer for Educational Programmes, a Training Programme Director for paediatrics and child health in London and an Associate Editor for the Postgraduate Medical Journal. DEL is the Chair of the RCPCH Trainees' Committee. CK is the Head of School for Paediatrics and Child Health in London.

Provenance and peer review Commissioned; externally peer reviewed.
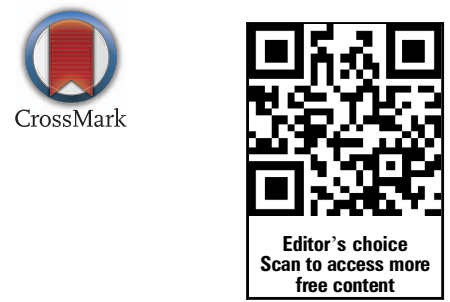

To cite Klaber RE, Lumsden DE, Kingdon C. Arch Dis Child 2015;100:119-120.

Received 31 August 2014

Revised 2 November 2014

Accepted 3 November 2014

Published Online First 20 November 2014

Arch Dis Child 2015;100:119-120.

doi:10.1136/archdischild-2014-305950

\section{REFERENCES}

1 Collins J. Foundation for excellence: an evaluation of the foundation programme. Medical Education England, 2010.

2 Department of Health. Modernising medical careers: the response of the four UK health ministers to the consultation on unfinished business: proposals for reform of the senior house officer grade. London, UK: Department of Health, 2003.

3 Tooke J. Aspiring to excellence: findings and recommendations of the independent inquiry into modernising medical careers. London: Aldridge Press, 2008.

4 Temple J. Time for training. Medical Education England, 2010. http://www.mee.nhs.uk/PDF/14274\% 20Bookmark\%20Web\%20Version.pdf (accessed 22 Aug 2014).

5 Greenaway D. Shape of training review: securing the future of excellent patient care. General Medical Council, 2013. http://www.shapeoftraining.co.uk/ static/documents/content/Shape_of_training_FINAL Report.pdf_53977887.pdf (accessed 22 Aug 2014).

6 RCPCH. Medical workforce census 2011. London: RCPCH, June 2013. http://www.rcpch.ac.uk/system/ files/protected/page/RCPCH\%20census\%20FINAL_0. pdf (accessed 22 Aug 2014).

7 Macaulay C, Klaber B, Spicer J, et al. Learning together in paediatric outreach clinics. Med Educ 2013:47:1134-5.

8 Deverill J. Connecting care for children: bridging the gap in North West London. National Health Executive, 2014. http://www.nationalhealthexecutive.com/Login aspx?ReturnUrl=\%2fComment\%2fconnecting-care-forchildren-bridging-the-gap-in-north-west-london (accessed 22 Aug 2014).

9 Klaber RE. Training and learning for the future: making change happen. Postgrad Med J 2014;90: 183-4. 